\title{
A Comparative Study on Bio-Inspired Algorithms in Layout Optimization of Construction Site Facilities
}

\author{
Prayogo, D. ${ }^{*}$, Sutanto, J.C. ${ }^{1}$, Suryo, H.E. ${ }^{1}$, and Eric, S. ${ }^{1}$
}

\begin{abstract}
A good arrangement of site layout on a construction project is a fundamental component of the project's efficiency. Optimization on site layout is necessary in order to reduce the transportation cost of resources or personnel between facilities. Recently, the use of bioinspired algorithms has received considerable critical attention in solving the engineering optimization problem. These methods have consistently provided better performance than traditional mathematical-based methods to a variety of engineering problems. This study compares the performance of particle swarm optimization (PSO), artificial bee colony (ABC), and symbiotic organisms search (SOS) algorithms in optimizing site layout planning problems. Three real-world case studies of layout optimization problems have been used in this study. The results show that SOS has a better performance in comparison to the other algorithms. Thus, this study provides useful insights to construction practitioners in the industry who are involved in dealing with optimization problems.
\end{abstract}

Keywords: Site layout; optimization; bio-inspired algorithms; particle swarm optimization; artificial bee colony; symbiotic organisms search.

\section{Introduction}

The arrangement of site layout on a construction project greatly affects the efficiency of the project, and consequently its costs. The goal of site layout is to find the minimum operational cost through a set of site layout compositions. A layout can be labeled good if it can produce the most efficient operation that can reduce the overall project cost. Many factors can affect the operational cost of a construction project, for example the distance and frequency of traveling between each facility, the route used, etc [1]. Generally, project managers tend to use intuition and previous experiences as a reference for layout planning of the project facilities. However, this does not always guarantee the optimal layout planning solution. This encourages researchers to develop a number of methods that have the potential to produce an efficient project site layout.

Over the past few years, research into facility layout optimization has been conducted. The site layout problem is classified as a quadratic assignment problem (QAP), which is categorized as a non-linear optimization problem [2].

${ }^{1}$ Department of Civil Engineering, Faculty of Civil Engineering and Planning, Petra Christian University, Jalan Siwalankerto 121-131, Surabaya 60236. INDONESIA

* Corresponding author: prayogo@petra.ac.id

Note: Discussion is expected before November, $1^{\text {st }} 2018$, and will be published in the "Civil Engineering Dimension", volume 21, number 1, March 2019.

Received 12 September 2018; revised 16 September 2018; accepted 17 September 2018.
Many studies have utilized bio-inspired algorithms to solve various types of QAP. Hence, for the past few years, researchers have tried to solve the site layout problem using bio-inspired algorithms. One example of early research is the site layout optimization conducted by Yeh [3], who used the simulated annealing (SA) algorithm to solve the site layout problem. Another research study was conducted by $\mathrm{Li}$ and Love [4] using the genetic algorithm (GA) to find a solution to the site layout optimization problem. They concluded that GA had an advantage in terms of global search compared to local search. Thus, the use of bio-inspired algorithms enables the site layout problem to be solved well, and at the same time uses a reasonable computation cost.

Recently, many researchers have been rigorously investigating the comparative performance between multiple bio-inspired algorithms in addressing the site layout problem. Adrian et al. [5] compared the performance of three bio-inspired algorithms when used to solve the site layout problem, namely GA, particle swarm optimization (PSO), and ant colony optimization (ACO). They compared the results from these three methods, showing that the ACO method was able to obtain the optimum solution within a shorter time in comparison with PSO and GA. Yahya and Saka [6] used artificial bee colony (ABC) and ant system (AS) algorithms to solve the layout planning problem of residential building and private hospital projects with multiple objective criteria. It was shown that the $\mathrm{ABC}$ outperformed the AS. Prayogo et al. [7] utilized differential evolution (DE), PSO, and symbiotic organisms search (SOS) to 
search for the best site layout of caisson structure fabrication. The result showed that SOS achieved the best overall performance.

Current bio-inspired optimization algorithms are diverse, with their own characteristics. Bio-inspired algorithms that are commonly used such as PSO, $\mathrm{ABC}$, and SOS have strengths and weaknesses when compared with each other. As construction projects become larger, the complexity of the site layout problem increases. For every site layout problem, every bio-inspired algorithm may produce a different performance. Thus, it is worthwhile continuing to investigate the best possible method to solve the more complex layout planning problem.

\section{Bio-inspired Optimization Algorithms}

The project facility site layout optimization process is not simple, so in this research bio-inspired optimization algorithm is used. It is an algorithm inspired by natural events that happen around us. For over three decades, various methods have been developed to help researchers improve optimization methods. In this research, the bio-inspired algorithms used are particle swarm optimization (PSO), artificial bee colony (ABC), and symbiotic organisms search (SOS).

\section{Particle Swarm Optimization}

First introduced by Kennedy and Eberhart [8], PSO adopts the principle of social group intelligence between living things. PSO imitates the behavior of a group of living things such as birds or fish when looking for food, where the behavior of each individual will affect one another. Particles will be generated in the first phase randomly, and will spread at a certain search location, with each particle representing a possible solution to a problem. In each iteration, every particle will move according to a speed vector, and is always renewed by a mathematical operator that models a social group relation shown in Equation (1). If a particle reaches a more optimal location, the position and objective value of that location (personal best) will be saved as pbest $X$ and pbestFv, respectively. In each iteration, the position and objective value of global best of all particles are saved as gbest $X$ and gbestFv.

$$
\begin{aligned}
& V_{i}=W^{*} V i+\operatorname{rand}(0,1) * C_{1} *\left(\text { pbest } X_{i}-X_{i}\right)+ \\
& \operatorname{rand}(0,1) * C_{2} *\left(\text { gbest } X-X_{i}\right)
\end{aligned}
$$

where $V_{i}$ is the speed of particle $i, W$ is the inertia weight parameter, $C_{1}$ is the cognitive factor parameter, pbest $X_{i}$ is the location coordinate of personal best, $X_{i}$ is the coordinate of particle $i, C_{2}$ is the social factor parameter, and gbest $X$ is the location coordinate of global best. The PSO algorithm calculation process flowchart is shown in Figure 1.

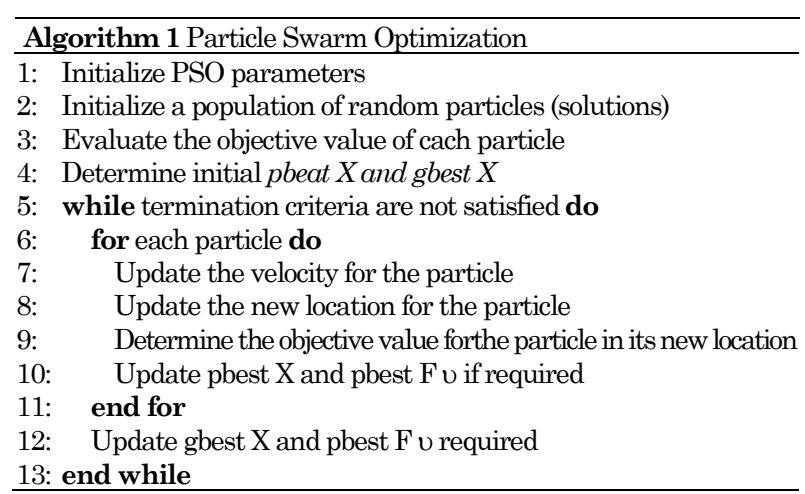

Figure 1. Pseudo-code of PSO

\section{Artificial Bee Colony}

$\mathrm{ABC}$ is a swarm intelligence-based algorithm introduced by Karaboga and Basturk [9] in 2007. ABC imitates the behavior of a bee colony in search of a food source. First, the ABC algorithm initializes the food source randomly containing a random variable as a candidate solution. After the food source has been determined, $\mathrm{ABC}$ enters the first phase, which involves the employed bees. In this stage, the bees make modifications to the candidate solution by looking for alternative solutions around it. In the modified solution, the objective value is measured first as information that will later be shared to the onlooker bees through a waggle dance as seen in Equation (2). In the onlooker-bees phase, the solution modified by the employed bees will be chosen randomly with a certain probability. Then the onlooker bees will further modify the solution based on the information received from the employed bees. In the scout bees phase, the employed bees turn into scout bees that look for an alternative solution, if the solution does not improve within a certain period of time. $A B C$ will stop the optimization process if a certain objective value is obtained, or it reaches the maximum iteration.

newFood $_{i}=$ Food $_{i}+\operatorname{rand}(-1,1) *\left(\right.$ Food $_{i}-$ Food $\left._{j}\right)$

where Food $_{i}$ is the food source at $i$, newFood $_{i}$ is the modified food source at $i$ after the onlooker bees phase, and Food $j$ is the food source at $j$ chosen at random. The pseudo-code of the $\mathrm{ABC}$ algorithm is shown in Figure 2.

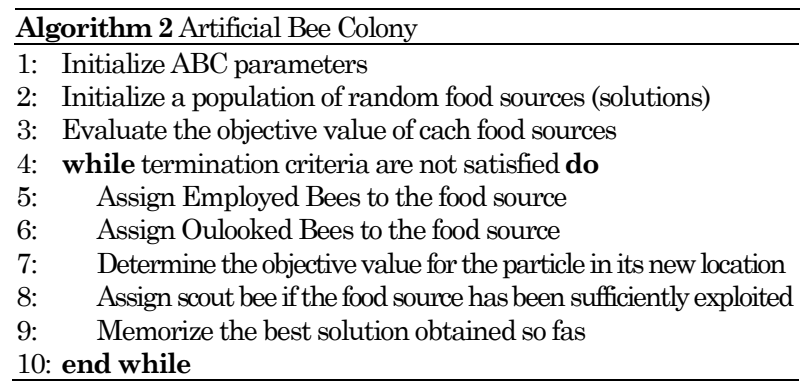

Figure 2. Pseudo-code of ABC 


\section{Symbiotic Organisms Search}

SOS was first introduced by Cheng and Prayogo [10] in 2014. It is one of the bio-inspired algorithms that simulates multiple symbiotic interactions between a pair of organisms in an ecosystem. In the SOS algorithm, these symbiotic interactions are defined in three phases, namely the mutualism phase, the commensalism phase, and the parasitism phase. The SOS algorithm is commonly used to solve continuous-based problems. Differing from evolutionarybased algorithms, the SOS algorithm does not produce offspring. However, like population-based algorithms, initially SOS will create a population (called an ecosystem), and through various search operators will try to modify the population iteratively in order to produce an optimum variables solution (called an organism). From the time it was introduced in 2014, many studies have utilized SOS to solve optimization problems in engineering research fields [7, 11$16]$.

During the mutualism phase, organism i $\left(O_{i}\right)$ will interact in a mutualism interaction with another organism $\left(O_{j}\right)$ in a random manner within an ecosystem to improve their individual quality within the ecosystem. Afterwards, two variable solutions are formed, new $O_{i}$ and new $O_{j}$ through a modification phase using the following mathematical equations:

new $O_{i}=O_{i}+\operatorname{rand}(0,1) *\left[O_{\text {best }}-\left(O_{i}+O_{j}\right) / 2 *(1+\right.$ round $(\operatorname{rand}(0,1))]$

new $O_{j}=O_{j}+\operatorname{rand}(0,1) *\left[O_{\text {best }}-\left(O_{i}+O_{j}\right) / 2 *(1+\right.$ round $(\operatorname{rand}(0,1))]$

$O_{\text {best }}$ are involved in these two mathematical equations, which is the organism with the best objective value in the ecosystem. If the objective values of the variable solutions new $O_{i}$ and new $O_{j}$ are more optimal than the objective values of $O_{i}$ and $O_{j}$, then the organisms $O_{i}$ and $O_{j}$ will be renewed.

During the commensalism phase, the organism $O_{i}$ will interact in a commensalism interaction with another organism $O_{j}$ that is randomly chosen. In this phase, organism $O_{i}$ takes an advantage from the interaction with $O j$, but organism $O_{j}$ is given neither an advantage or a disadvantage. Variable solution $n e w O_{i}$ is formed in this phase from a mathematical equation as follows.

$$
\text { new } O_{i}=O_{i}+\operatorname{rand}(-1,1) *\left(O_{\text {best }}-O_{j}\right)
$$

If the objective value of the variable solution new $O_{i}$ from the modification process is more optimal than the objective value of $O_{i}$, then the organism $O_{i}$ will be renewed.

During the parasitism phase, organism $O_{i}$ produces an artificial parasite called $O_{\text {parasite. }}$ It is created as a result of the combination of cloning of the organism
$O_{i}$ and random variables. Organism $O_{j}$ acts as a host and is chosen at random from the ecosystem. After the objective evaluation, the objective value between $O_{\text {parasite }}$ and organism $O_{j}$ is compared. If the objective value of the $O_{\text {parasite }}$ is better than the organism $O_{j}$, then the $O_{\text {parasite }}$ replaces the position of $O_{j}$ in the ecosystem. Otherwise, the organism $O_{j}$ retains its position if its objective value is better. The SOS algorithm calculation process flowchart is shown in Figure 3.

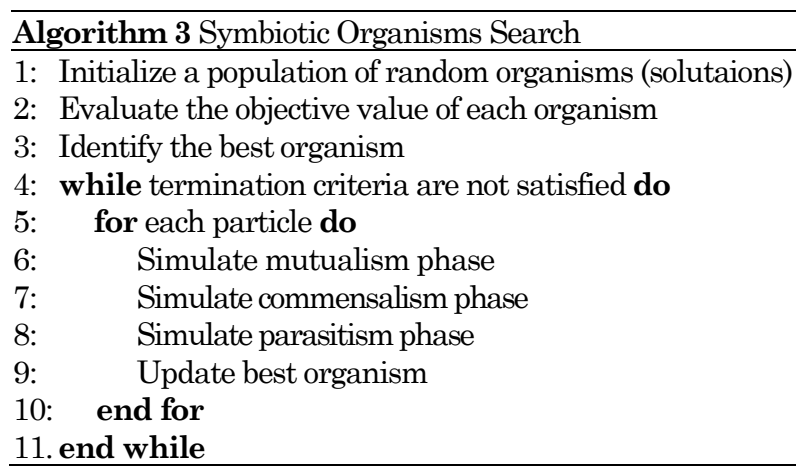

Figure 3. Pseudo-code of SOS

\section{Construction Site Layout Planning Optimization}

\section{Mathematical Optimization Model}

The site layout of construction facilities greatly affects the productivity of construction personnel, therefore determining the optimization model of the layout planning problem is necessary. In designing the site layout of facilities, the identification of distance and frequency between each facility, and the number of workspaces available are needed. There are two conditions in site layout placement; unequalarea facility site layout and equal-area facility site layout. Unequal-area facility site layout is a condition where the number of workspaces is not proportional to the number of project facilities, while equal-area facility site layout is a condition where the number of workspaces is proportional to the number of project facilities [4]. The main purpose of construction facility site layout planning is to determine the project facility placement $(n)$ on the available workspace $(m)$ that minimizes the workers' traveling distance between each facility. The construction site layout planning problem is modeled as a quadratic assignment problem that uses the traveling distance and traveling frequency of workers as the main key to obtain the optimum result.

$$
\text { Minimize } T D=\sum_{i=1}^{n} \sum_{j=1}^{n} \sum_{k=1}^{n} \sum_{l=1}^{n} f_{i k} d_{j l} x_{i j} x_{k l}
$$

Subject to $\sum_{j=1}^{n} x_{i j}=1, i=1,2,3, \ldots, n$ 
$\sum_{i=1}^{n} x_{i j}=1, j=1,2,3, \ldots, n$

$x_{i j} \in\{0,1\}, i=1,2,3, \ldots, n, j=1,2,3, \ldots, n$

$n$ is the total number of facilities that will be placed, $d_{i j}$ is the distance between the location of facility $i$ and facility $j$, while $f_{i j}$ is the traveling frequency between facility $i$ and facility $j$. If two facilities are placed next to each other, then the traveling distance between the two facilities is measured from the midpoint of the two facilities. If not, then the traveling distance between the two facilities can be measured by the total segmental distance between the two facilities, as an example, the distance between facilities 1 and 3, then the distance between the two is the total of distance between facilities 1 and 2 and the distance between facilities 2 and 3 .

\section{Experimental Results}

This research compares the ability of three bioinspired algorithms, namely PSO, ABC, and SOS using three case studies. The first is a hypothetical case taken from $\mathrm{Li}$ and Love [12], with 11 facilities and 11 locations. The second is a layout problem with 10 facilities and 10 locations from an apartment building project in Surabaya, Indonesia, obtained from Prayogo et al. [13]. The third is obtained from a hotel building project in Surabaya, Indonesia, with 14 facilities and 14 locations. Every case study has several permanent locations that act as a constraint to determine the facility location. The parameters used in each algorithm are shown in Table 1.

Every algorithm is simulated 30 times to remove the random bias with 30 iterations (maxiter) and 50 populations (popsize) for each simulation. PSO and $\mathrm{ABC}$ have additional algorithm-specific parameters. For PSO, cognitive $\left(C_{1}\right)$ and social factor $\left(C_{2}\right)$ parameters is set to 2 and 2, respectively. For ABC, the limit parameter for scout bees phase is set to be 100 . The result obtained by running the three algorithms is the total traveling distance or the best traveling distance by arranging the locations of each facility so that they are the most effective for workers, as shown in Equations (6) - (9).

Table 1. Parameter of Bio-inspired Algorithms

\begin{tabular}{ccc}
\hline PSO & ABC & SOS \\
\hline$C_{1}=2$ & & \\
$C_{2}=2$ & limit $=100$ & popsize $=30$ \\
$W=0.4-0.9$ & popsize $=30$ & maxiter $=30$ \\
popsize $=30$ & maxiter $=30$ & \\
maxiter $=30$ & & \\
\hline
\end{tabular}

Case Study 1: Layout Planning Problem with 11 Facilities

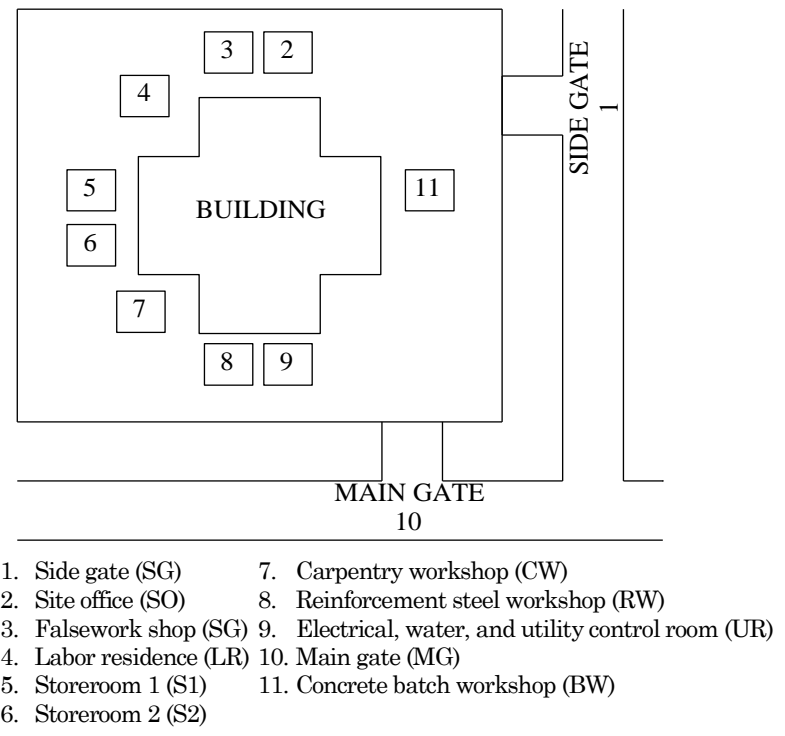

Figure 4. A Hypothetical of Site Layout of Case Study 1

The first case study was introduced by $\mathrm{Li}$ and Love [17] and has 11 facilities to be arranged in 11 locations. The side gate is placed permanently in location 1 and the main gate is placed permanently in location 10. The locations of the facilities are shown in Figure 4. The traveling distance and the traveling frequencies between each location are shown in Table 2 and Table 3 respectively.

Table 2. Traveling Distance (in meters) between Each Location for Case Study 1

\begin{tabular}{crrrrrrrrrrr}
\hline Location & 1 & 2 & 3 & 4 & 5 & 6 & 7 & 8 & 9 & 10 & 11 \\
\hline 1 & 0 & 15 & 25 & 33 & 40 & 42 & 47 & 55 & 35 & 30 & 20 \\
2 & 15 & 0 & 10 & 18 & 25 & 27 & 32 & 42 & 50 & 45 & 35 \\
3 & 25 & 10 & 0 & 8 & 15 & 17 & 22 & 32 & 52 & 55 & 45 \\
4 & 33 & 18 & 8 & 0 & 7 & 9 & 14 & 24 & 44 & 49 & 53 \\
5 & 40 & 25 & 15 & 7 & 0 & 2 & 7 & 17 & 37 & 42 & 52 \\
6 & 42 & 27 & 17 & 9 & 2 & 0 & 5 & 15 & 35 & 40 & 50 \\
7 & 47 & 32 & 22 & 14 & 7 & 5 & 0 & 10 & 30 & 35 & 40 \\
8 & 55 & 42 & 32 & 24 & 17 & 15 & 10 & 0 & 20 & 25 & 35 \\
9 & 35 & 50 & 52 & 44 & 37 & 35 & 30 & 20 & 0 & 5 & 15 \\
10 & 30 & 45 & 55 & 49 & 42 & 40 & 35 & 25 & 5 & 0 & 10 \\
11 & 20 & 35 & 45 & 53 & 52 & 50 & 40 & 35 & 15 & 10 & 0 \\
\hline
\end{tabular}

Table 3. Traveling Frequency between Each Location for Case Study 1

\begin{tabular}{lccccccccccc}
\hline \multicolumn{1}{c}{ Facility } & SO & FS & LR & S1 & S2 & CW & RW & SG & UR & BW & MG \\
\hline SO & 0 & 5 & 2 & 2 & 1 & 1 & 4 & 1 & 2 & 9 & 1 \\
FS & 5 & 0 & 2 & 5 & 1 & 2 & 7 & 8 & 2 & 3 & 8 \\
LR & 2 & 2 & 0 & 7 & 4 & 4 & 9 & 4 & 5 & 6 & 5 \\
S1 & 2 & 5 & 7 & 0 & 8 & 7 & 8 & 1 & 8 & 5 & 1 \\
S2 & 1 & 1 & 4 & 8 & 0 & 3 & 4 & 1 & 3 & 3 & 6 \\
CW & 1 & 2 & 4 & 7 & 3 & 0 & 5 & 8 & 4 & 7 & 5 \\
RW & 4 & 7 & 9 & 8 & 4 & 5 & 0 & 7 & 6 & 3 & 2 \\
SG & 1 & 8 & 4 & 1 & 1 & 8 & 7 & 0 & 9 & 4 & 8 \\
UR & 2 & 2 & 5 & 8 & 3 & 4 & 6 & 9 & 0 & 5 & 3 \\
BW & 9 & 3 & 6 & 5 & 3 & 7 & 3 & 4 & 5 & 0 & 5 \\
MG & 1 & 8 & 5 & 1 & 6 & 5 & 2 & 8 & 3 & 5 & 0 \\
\hline
\end{tabular}


For the first case, the comparison of the results after 30 simulations is shown in Table 4. The location for each facility and the optimum traveling distance are shown in Table 5 and Figure 5. Although PSO, ABC, and SOS have achieved the same best design, SOS was better in terms of consistency, able to yield the lowest average and standard deviation.

Table 4. Total Traveling Distance Comparison for Case Study 1

\begin{tabular}{ccccc}
\hline Methods & $\begin{array}{c}\text { Minimum Maximum } \\
(\mathrm{m})\end{array}$ & $\begin{array}{c}\text { Average } \\
(\mathrm{m})\end{array}$ & $\begin{array}{c}\text { Standard } \\
\text { Deviation }(\mathrm{m})\end{array}$ \\
\hline PSO & 12546 & 12840 & 12583 & 70.321 \\
ABC & 12546 & 13190 & 12812.07 & 169.552 \\
SOS & 12546 & 12714 & 12560.07 & 39.953 \\
\hline
\end{tabular}

Table 5. Location and Optimum Traveling Distance Value Comparison for Case Study 1

\begin{tabular}{|c|c|c|c|c|c|c|c|c|c|c|c|c|}
\hline Methods & $\mathrm{SO}$ & FS & & $\mathrm{S} 1$ & S2 & CW & RW & SG & UR & 20 & & $\begin{array}{l}\text { Traveling } \\
\text { Distance } \\
\text { (m) }\end{array}$ \\
\hline PSO & 9 & & & 6 & 7 & 2 & 4 & 1 & 3 & 8 & 10 & 12546 \\
\hline $\mathrm{ABC}$ & 9 & 11 & 4 & 5 & 7 & 6 & 3 & 1 & 2 & 8 & 10 & 12546 \\
\hline SOS & 9 & 11 & 4 & 6 & 7 & 5 & 3 & 1 & 2 & 8 & 10 & 12546 \\
\hline
\end{tabular}

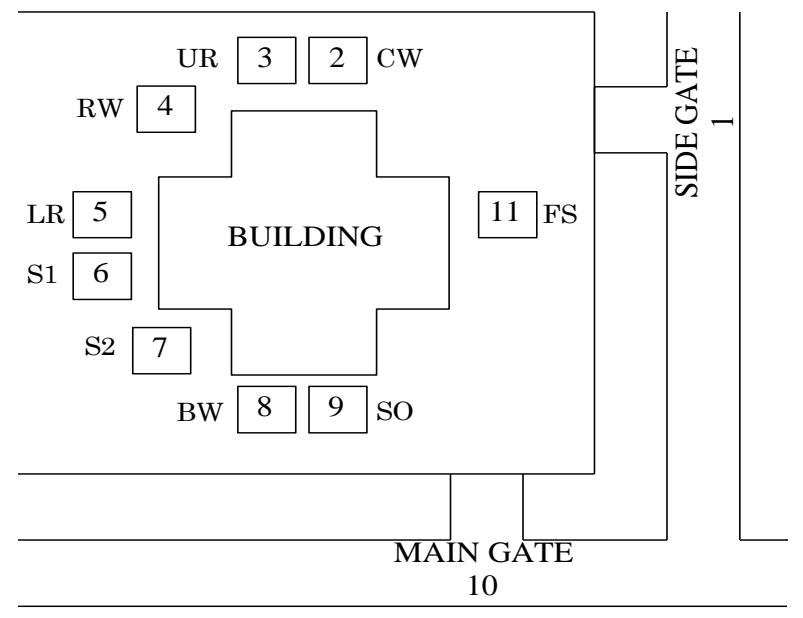

Figure 5. Best Layout Design of PSO, ABC, and SOS

\section{Case Study 2: Layout Planning Problem with 10 facilities}

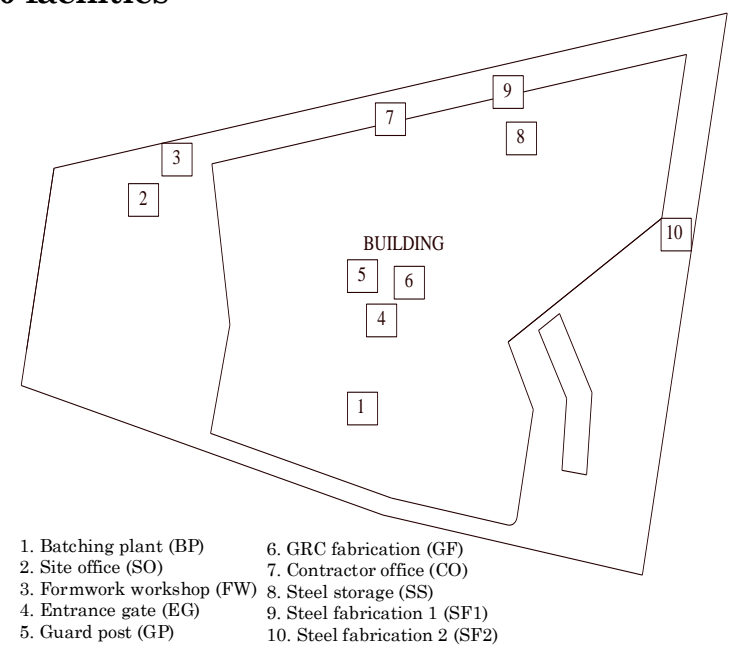

Figure 6. Original Site Layout of Case Study 2
The second case study was introduced by Prayogo et al. [13] and has 10 facilities to be arranged in 10 locations. The entrance gate is placed permanently in location 4 and the guard post is placed permanently in location 5. The locations of the facilities are shown in Figure 6. The traveling distance and the traveling frequencies between each location are shown in Table 6 and Table 7 respectively.

Table 6. Traveling Distance (in meters) between Each Location for Case Study 2

\begin{tabular}{crrrrrrrrrr}
\hline Location & 1 & 2 & 3 & 4 & 5 & 6 & 7 & 8 & 9 & 10 \\
\hline 1 & 0 & 139 & 156 & 33 & 39 & 49 & 139 & 170 & 174 & 150 \\
2 & 139 & 0 & 19 & 106 & 100 & 112 & 128 & 160 & 165 & 188 \\
3 & 156 & 19 & 0 & 125 & 119 & 131 & 112 & 144 & 148 & 207 \\
4 & 33 & 106 & 125 & 0 & 12 & 23 & 111 & 143 & 147 & 123 \\
5 & 39 & 100 & 119 & 12 & 0 & 12 & 99 & 131 & 135 & 111 \\
6 & 49 & 112 & 131 & 23 & 12 & 0 & 89 & 121 & 125 & 101 \\
7 & 138 & 128 & 112 & 111 & 99 & 89 & 0 & 32 & 36 & 104 \\
8 & 170 & 160 & 144 & 143 & 131 & 121 & 32 & 0 & 9 & 42 \\
9 & 174 & 165 & 148 & 147 & 135 & 125 & 36 & 9 & 0 & 102 \\
10 & 150 & 188 & 207 & 123 & 111 & 101 & 104 & 42 & 102 & 0 \\
\hline
\end{tabular}

Table 7. Traveling Frequency between Each Location for Case Study 2

\begin{tabular}{lrrrrrrrrrr}
\hline \multicolumn{1}{c}{ Facility } & BP & \multicolumn{1}{c}{ SO } & FW & EG & GP & GF & CO & \multicolumn{3}{r}{ SS SF1 } \\
\hline BP & 0 & 10 & 8 & 9 & 3 & 9 & 0 & 0 & 0 & 0 \\
SO & 10 & 0 & 8 & 12 & 8 & 9 & 11 & 5 & 0 & 1 \\
FW & 8 & 8 & 0 & 4 & 3 & 8 & 0 & 0 & 0 & 0 \\
EG & 9 & 12 & 4 & 0 & 6 & 15 & 10 & 10 & 8 & 5 \\
GP & 3 & 8 & 3 & 6 & 0 & 9 & 5 & 3 & 2 & 1 \\
GF & 9 & 9 & 8 & 15 & 9 & 0 & 0 & 0 & 0 & 0 \\
CO & 0 & 11 & 0 & 10 & 5 & 0 & 0 & 7 & 7 & 10 \\
SS & 0 & 5 & 0 & 10 & 3 & 0 & 7 & 0 & 25 & 27 \\
SF1 & 0 & 0 & 0 & 8 & 2 & 0 & 7 & 25 & 0 & 16 \\
SF2 & 0 & 1 & 0 & 5 & 1 & 0 & 10 & 27 & 16 & 0 \\
\hline
\end{tabular}

For the second case, the comparison of the results after 30 simulations is shown in Table 8. The location for each facility and the optimum traveling distance are shown in Table 9 and Figure 7 . Although PSO, ABC, and SOS have achieved the same best design, SOS was better in terms of consistency, able to yield the lowest average and standard deviation.

Table 8. Total Traveling Distance Comparison for Case Study 2

\begin{tabular}{|c|c|c|c|c|}
\hline Methods & $\begin{array}{l}\text { Minimum } \\
(\mathrm{m})\end{array}$ & $\begin{array}{l}\text { Maximum } \\
(\mathrm{m})\end{array}$ & $\begin{array}{l}\text { Average } \\
(\mathrm{m})\end{array}$ & $\begin{array}{c}\text { Standard } \\
\text { Deviation }(\mathrm{m})\end{array}$ \\
\hline PSO & 39184 & 40736 & 39327.07 & 303.011 \\
\hline $\mathrm{ABC}$ & 39184 & 46698 & 41733.77 & 2013.849 \\
\hline SOS & 39184 & 40666 & 39243.4 & 274.206 \\
\hline
\end{tabular}

Table 9. Location and Optimum Traveling Distance Value Comparison for Case Study 2

Methods BP SO FW EG GP GF CO SS SF1 SF2 Traveling

\begin{tabular}{cccccccccccc} 
PSO & 2 & 6 & 3 & 4 & 5 & 1 & 10 & 7 & 9 & 8 & 39184 \\
$\mathrm{ABC}$ & 2 & 6 & 3 & 4 & 5 & 1 & 10 & 7 & 9 & 8 & 39184 \\
$\mathrm{SOS}$ & 2 & 6 & 3 & 4 & 5 & 1 & 10 & 7 & 9 & 8 & 39184 \\
\hline
\end{tabular}




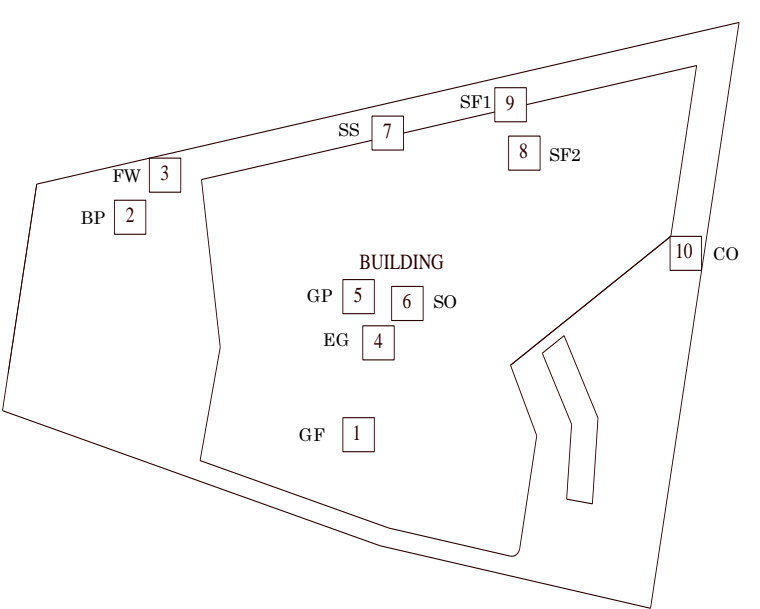

Figure 7. Best Layout Design of PSO, ABC, and SOS

\section{Case Study 3: Layout Planning Problem with} 14 Facilities

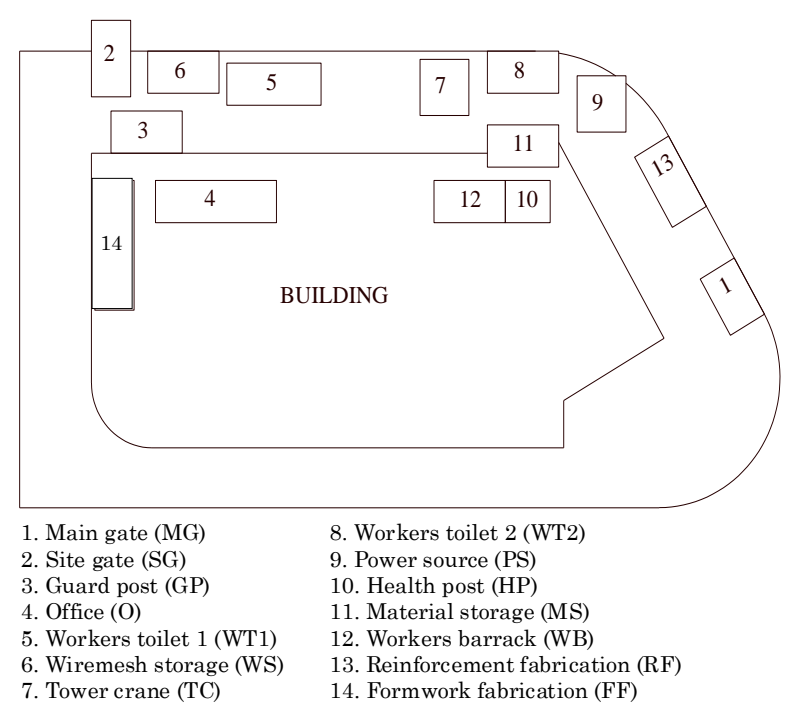

Figure 8. Original Site Layout of Case Study 3

Table 10. Traveling Distance (in meters) between Each Location for Case Study 3

\begin{tabular}{crrrrrrrrrrrrrr}
\hline Location & 1 & 2 & 3 & 4 & 5 & 6 & 7 & 8 & 9 & 10 & 11 & 12 & 13 & 14 \\
\hline 1 & 0 & 65 & 60 & 43 & 38 & 37 & 25 & 17 & 10 & 8 & 11 & 17 & 0 & 51 \\
2 & 65 & 0 & 7 & 14 & 15 & 7 & 23 & 33 & 51 & 45 & 40 & 36 & 47 & 15 \\
3 & 60 & 7 & 0 & 7 & 12 & 4 & 20 & 30 & 43 & 37 & 31 & 28 & 45 & 8 \\
4 & 43 & 14 & 7 & 0 & 9 & 9 & 12 & 23 & 26 & 20 & 15 & 11 & 32 & 6 \\
5 & 38 & 15 & 12 & 9 & 0 & 2 & 4 & 14 & 22 & 23 & 15 & 14 & 34 & 18 \\
6 & 37 & 7 & 4 & 9 & 2 & 0 & 8 & 18 & 26 & 25 & 19 & 18 & 35 & 12 \\
7 & 25 & 23 & 20 & 12 & 4 & 8 & 0 & 2 & 10 & 10 & 6 & 10 & 12 & 28 \\
8 & 17 & 33 & 30 & 23 & 14 & 18 & 2 & 0 & 8 & 9 & 5 & 13 & 10 & 38 \\
9 & 10 & 51 & 43 & 26 & 22 & 26 & 10 & 8 & 0 & 12 & 5 & 15 & 1 & 42 \\
10 & 8 & 45 & 37 & 20 & 23 & 25 & 10 & 9 & 12 & 0 & 1 & 9 & 6 & 36 \\
11 & 11 & 42 & 34 & 15 & 15 & 19 & 6 & 5 & 5 & 1 & 0 & 6 & 4 & 36 \\
12 & 17 & 36 & 28 & 11 & 14 & 18 & 10 & 13 & 15 & 9 & 6 & 0 & 15 & 27 \\
13 & 0 & 47 & 45 & 32 & 34 & 35 & 12 & 10 & 1 & 6 & 4 & 15 & 0 & 51 \\
14 & 51 & 15 & 8 & 6 & 18 & 12 & 28 & 38 & 42 & 36 & 36 & 27 & 51 & 0 \\
\hline
\end{tabular}

This case study has 14 facilities to be arranged in 14 locations. The main gate is placed permanently in location 1 , the side gate is placed permanently in location 2 , the tower crane is placed permanently in location 7, and the power source is placed permanently in location 9. The locations of the facilities are shown in Figure 8. The traveling distance and the traveling frequencies between each location are shown in Table 10 and Table 11 respectively.

Table 11. Traveling Frequency between Each Location for Case Study 3

\begin{tabular}{lrrrrrrrrrrrrrr}
\hline Facility & MG & SGGP & O & WT1 & WS & TC & WT2 & PS & MS WB & RFF \\
\hline MG & 0 & 0 & 0 & 0 & 0 & 0 & 0 & 0 & 0 & 0 & 0 & 0 & 0 & 0 \\
SG & 0 & 0 & 1 & 1 & 1 & 30 & 1 & 1 & 1 & 3 & 15 & 2 & 2 & 0 \\
GP & 0 & 1 & 0 & 1 & 0 & 0 & 1 & 1 & 1 & 1 & 1 & 1 & 1 & 0 \\
O & 0 & 1 & 1 & 0 & 3 & 1 & 1 & 1 & 1 & 2 & 2 & 3 & 2 & 2 \\
WT1 & 0 & 1 & 0 & 3 & 0 & 0 & 1 & 0 & 0 & 2 & 0 & 4 & 0 & 0 \\
WS & 0 & 30 & 0 & 1 & 0 & 0 & 0 & 1 & 0 & 4 & 2 & 4 & 4 & 0 \\
TC & 0 & 1 & 1 & 1 & 1 & 0 & 0 & 1 & 1 & 1 & 0 & 1 & 0 & 0 \\
WT2 & 0 & 1 & 1 & 1 & 0 & 1 & 1 & 0 & 1 & 2 & 2 & 2 & 2 & 2 \\
PS & 0 & 1 & 1 & 1 & 0 & 0 & 1 & 1 & 0 & 0 & 0 & 1 & 0 & 0 \\
HP & 0 & 3 & 1 & 2 & 2 & 4 & 1 & 2 & 0 & 0 & 3 & 3 & 2 & 2 \\
MS & 0 & 15 & 1 & 2 & 0 & 2 & 0 & 2 & 3 & 3 & 0 & 2 & 15 & 2 \\
WB & 0 & 2 & 1 & 3 & 4 & 4 & 1 & 2 & 3 & 3 & 2 & 0 & 2 & 2 \\
RF & 0 & 2 & 1 & 2 & 0 & 4 & 0 & 2 & 2 & 2 & 15 & 2 & 0 & 0 \\
FF & 0 & 0 & 0 & 2 & 0 & 0 & 0 & 2 & 2 & 2 & 2 & 2 & 0 & 0 \\
\hline
\end{tabular}

For the third case, the comparison of the results after 30 simulations is shown in Table 12. The location for each facility and the optimum traveling distance are shown in Table 13. From Table 13, it can be seen that PSO can achieve the best layout design (see Figure 9) in comparison with ABC (see Figure 10) and SOS (see Figure 11). However, SOS achieve the lowest average and standard deviation, indicating that SOS is the most consistent algorithm among the bio-inspired algorithms.

Table 12. Total Traveling Distance Comparison for Case Study 3

\begin{tabular}{lcccc}
\hline Methods & $\begin{array}{c}\text { Minimum Maximum } \\
(\mathrm{m})\end{array}$ & $\begin{array}{c}\text { Average } \\
(\mathrm{m})\end{array}$ & $\begin{array}{c}\text { Standard } \\
\text { Deviation }(\mathrm{m})\end{array}$ \\
\hline PSO & 4276 & 4973 & 4553.933 & 159.392 \\
ABC & 4391 & 4932 & 4662.467 & 157.698 \\
SOS & 4281 & 4531 & 4398.4 & 67.027 \\
\hline
\end{tabular}

Table 13. Location and Optimum Traveling Distance Value Comparison for Case Study 3

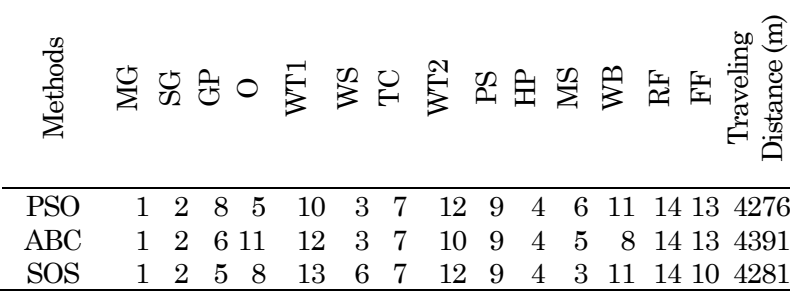

\section{Conclusion}

This research presents a comparative study of bioinspired algorithms on solving the facility layout planning problem of construction projects. Three bioinspired algorithms, namely PSO, ABC, and SOS, have been used to solve three separate case studies. 
It is found that the SOS algorithm is the best out of the three algorithms because it is able to find the most optimum solution. Thirty simulations have been conducted for each study. According to the results, most of the algorithms can find the best site layout of each case study. It is worth noting that SOS is the best performer in terms of consistency. SOS can find the lowest mean and standard deviation value for each problem.

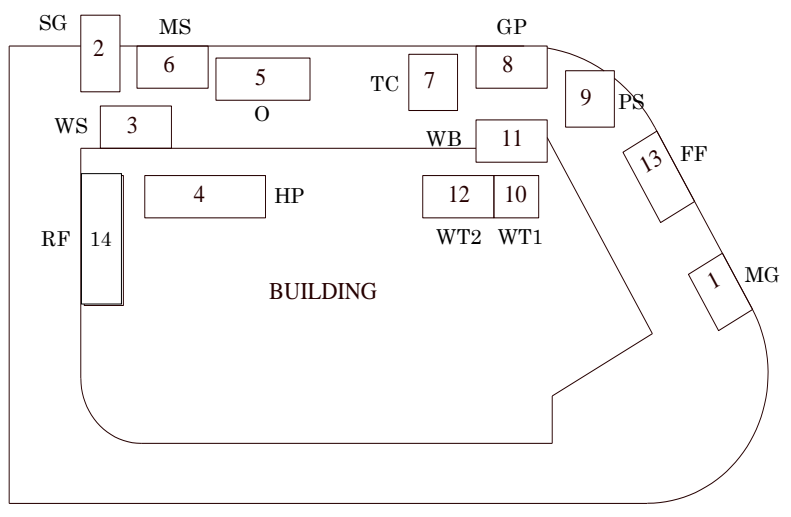

Figure 9. Best Layout Design of PSO

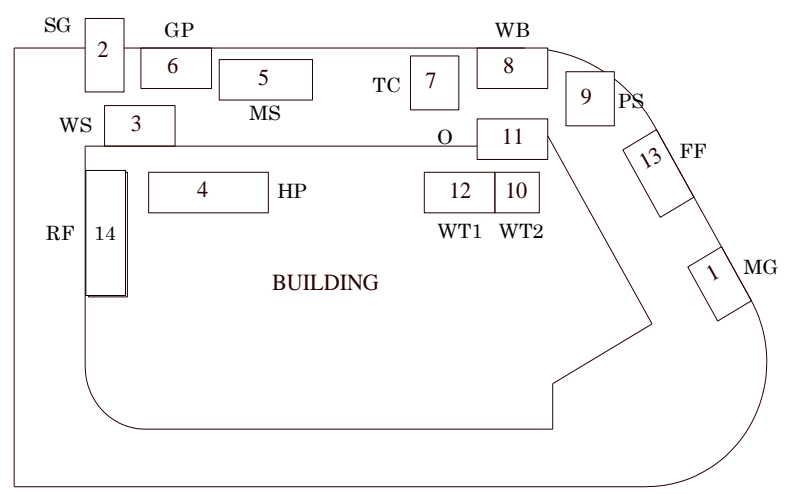

Figure 10. Best Layout Design of $\mathrm{ABC}$

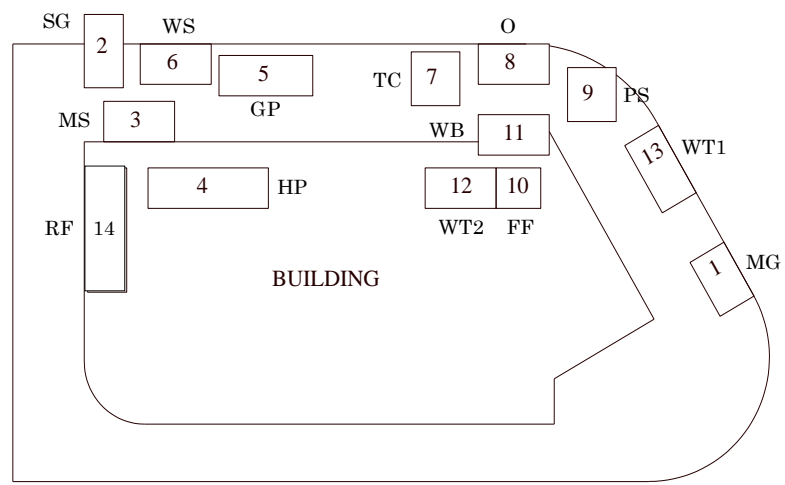

Figure 11. Best Layout Design of SOS

\section{Acknowledgment}

The authors gratefully acknowledge that the present research is financially supported by The Ministry of Research, Technology and Higher Education of the Republic of Indonesia under the PDUPT Research Grant Scheme (No. SP DIPA-042.06.1.401516/2018).

\section{References}

1. Tommelein, I., Levitt, R., and Hayes-Roth, B., Sight Plan Model for Site Layout, Journal of Construction Engineering and Management, 118(4), 1992, pp. 749-766.

2. Tate, D.M. and Smith, A.E., Unequal-Area Facility Layout by Genetic Search, IIE Transactions, 27(4), 1995, pp. 465-472.

3. Yeh, I.-C., Construction-Site Layout using Annealed Neural Network, Journal of Computing in Civil Engineering, 9(3), 1995, pp. 201-208.

4. Li, H. and Love, P.E.D., Genetic Search for Solving Construction Site-Level Unequal-Area Facility Layout Problems, Automation in Construction, 9(2), 2000, pp. 217-226.

5. Adrian, A.M., Utamima, A., and Wang, K.-J., A Comparative Study of GA, PSO and ACO for Solving Construction Site Layout Optimization, KSCE Journal of Civil Engineering, 19(3), 2015, pp. 520-527.

6. Yahya, M. and Saka, M.P., Construction Site Layout Planning using Multi-Objective Artificial Bee Colony Algorithm with Levy Flights, Automation in Construction, 38, 2014, pp. 14-29.

7. Prayogo, D., Cheng, M.-Y., and Prayogo, H., A Novel Implementation of Nature-Inspired Optimization for Civil Engineering: A Comparative Study of Symbiotic Organisms Search, Civil Engineering Dimension, 19(1), 2017, pp. 36-43.

8. Kennedy, J. and Eberhart, R., Particle Swarm Optimization, Proceedings of IEEE International Conference on Neural Networks, 1995, pp. 1942 1948.

9. Karaboga, D. and Basturk, B., A Powerful and Efficient Algorithm for Numerical Function Optimization: Artificial Bee Colony (ABC) Algorithm, Journal of Global Optimization, 39(3), 2007, pp. 459-471.

10. Cheng, M.-Y. and Prayogo, D., Symbiotic Organisms Search: A New Metaheuristic Optimization Algorithm, Computers \& Structures, 139, 2014, pp. 98-112.

11. Cheng, M.-Y., Prayogo, D., and Tran, D.-H., Optimizing Multiple-Resources Leveling in Multiple Projects using Discrete Symbiotic Organisms Search, Journal of Computing in Civil Engineering, 30(3), 2016, pp. 04015036.

12. Tran, D.-H., Cheng, M.-Y., and Prayogo, D., A Novel Multiple Objective Symbiotic Organisms Search (MOSOS) for Time-Cost-Labor Utilization Tradeoff Problem, Knowledge-based Systems, 94, 2016, pp. 132-145.

13. Prayogo, D., Gosno, R.A., Evander, R., and Limanto, S., Implementasi Metode Metaheuristik Symbiotic Organisms Search dalam Penentuan Tata Letak Fasilitas Proyek Konstruksi Berdasarkan Jarak Tempuh Pekerja, Jurnal Teknik Industri, 19(2), 2018, pp. 103-114. 
14. Prayogo, D., Metaheuristic-based Machine Learning System for Prediction of Compressive Strength Based on Concrete Mixture Properties and Early-Age Strength Test Results, Civil Engineering Dimension, 20(1), 2018, pp. 21-29.

15. Prayogo, D. and Susanto, Y.T.T., Optimizing the Prediction Accuracy of Friction Capacity of Driven Piles in Cohesive Soil using a Novel SelfTuning Least Squares Support Vector Machine, Advances in Civil Engineering, 2018, 2018.
16. Prayogo, D., Cheng, M.-Y., Wong, F.T., Tjandra, D., and Tran, D.-H., Optimization Model for Construction Project Resource Leveling Using a Novel Modified Symbiotic Organisms Search, Asian Journal of Civil Engineering, 19(5), 2018, pp. 625-638.

17. Li, H. and Love, P.E.D., Site-Level Facilities Layout using Genetic Algorithms, Journal of Computing in Civil Engineering, 12(4), 1998, pp. 227-231. 